\title{
HePATITIS B PROGRAM FOR ABORIGINAL CHILDREN
}

\section{INTRODUCTION}

$\mathrm{T}$ he NSW Aboriginal Health Resource Committee initiated a program to immunise Aboriginal children against hepatitis $B$ virus (HBV) infection. The program was conducted in the South West Health Region (SWR) between July 1990 and June 1991, and formed part of a national program to control hepatitis B, a major cause of ill-health facing Aboriginal communities ${ }^{1}$.

The program offered free hepatitis B immunisation to Aboriginal children aged from 0 to 12 years. Aboriginal Health Workers (AHWs), Aboriginal Health Nurses (AHNs), local Aboriginal communities, Community Health and Early Childhood Nurses (ECNs) combined to conduct the program.

\section{METHODS}

Before the program began, the staff involved consulted with representatives from Aboriginal land councils, community centres, community health centres and schools and sought their assistance in the provision of facilities and the communication of information to the Aboriginal community.

In Wagga Wagga and Albury AHWs visited schools and pre-schools attended by Aboriginal children, and with the permission of school principals identified eligible children and issued consent forms and information leaflets. Those children returning signed consent forms were included in the immunisation program. When the children attended the immunisation clinic at the school, some younger siblings were brought by parents and they were immunised also. In smaller communities eligible children were identified by the AHW, through the schools and also through contact with the local Aboriginal communities and community groups. The local ECN, the Regional AHN or the local AHW was responsible for the organisation of the program. Venues for immunisation clinics varied from schools to neighbourhood centres and other community facilities.

A three-dose immunisation schedule was used in the program which has been evaluated in terms of:

\section{- the percentage of children commencing the immunisation course who completed it, i.e. received the full three doses (the completion rate); and the estimated coverage of the eligible population in the South West Region.}

The completion rate was calculated as follows:

Completion rate $=$ number completing course $\times 100$

Percentage number commencing course

Data were derived from the immunisation register held by the Regional Hepatitis B Coordinator. For a number of locations, age details were unavailable and for one community no immunisation data were available. The number of eligible Aboriginal children was estimated using Australian Bureau of Statistics (ABS) data from the 1986 census. For this analysis the age groups 0-4 years and $5-12$ years have been used. Although it was not possible to calculate population coverage accurately, based on the 1986 census figures an approximate coverage rate was determined.

\section{RESULTS}

In total 852 children began immunisation courses and 656 received three doses, giving an overall completion rate of 77 per cent (with a range in different locations from 50-100 per cent, see Table 1). Five centres (Wagga Wagga, Albury, Griffith, Dareton and Narrandera) accounted for 70 per cent of all children starting the program. In the western part of the Region (Dareton, Wentworth and Buronga) the completion rate was only 65 per cent. Almost 25 per cent of children commencing the program were from these three communities. The completion rate in Griffith was lower than the other large centres (Wagga Wagga and Albury). In general, completion rates in centres with a smaller Aboriginal population (such as Brungle, Cootamundra and Hay) were high (Table 1).

While data on the age groups of children immunised under the program were not available for all centres, available data indicated the program identified a higher proportion of school-aged children (5-12 years) than preschoolers ( $0-4$ years). ABS data suggest pre-schoolers make up about 40 per cent of the Aboriginal children in the SWR in the 0-12 age group. Of the children in this program whose ages were known, fewer than 20 per cent were pre-schoolers. (Children identified and immunised under the high-risk neonate program are not included here.) There is also evidence that the completion rate was lower for the younger age group ( 75 per cent compared to 85 per cent, see Table 1).

Population estimates based on ABS data indicate that for the Region as a whole, a large proportion of the eligible children may not have been included in the program. Of an estimated 1,441 children eligible, 59 per cent were identified by the program and 46 per cent fully immunised. In addition 196 infants were identified under the high-risk neonate program between October 1987 and December 1990, with 119 being fully immunised. Including these figures raises the proportion of eligible children identified to 73 per cent, and the coverage rate with three doses to 54 per cent.

\section{DISCUSSION}

It is encouraging that 77 per cent of children who began immunisation under the program completed the course. However there was a poor completion rate in some communities with relatively large numbers of Aboriginal children, particularly in the western part of the Region. Despite the fairly high completion rate overall, a significant concern is the disparity between the numbers of children identified and estimates of the eligible population based on ABS census data for the Region. It is possible that large numbers of eligible children were not immunised under this program.

The results suggest that a larger proportion of children aged five years and over (i.e school age) were identified in the program, and that this age group had a higher completion rate. It was easier to locate, enrol and immunise students at school. Children aged under five 


\section{TABLE 1}

HEPATITIS B IMMUNISATION/COURSES

COMMENCED AND COMPLETED

BY AGE AND LOCATION

\begin{tabular}{|c|c|c|c|c|c|c|}
\hline \multirow[t]{2}{*}{ Location } & \multicolumn{2}{|c|}{$0-4$ years } & \multicolumn{2}{|c|}{$5-12$ years } & \multicolumn{2}{|c|}{ Total } \\
\hline & Commenced & Completed \% & Commenced & Completed \% & Commenced & Completed \% \\
\hline Wagga Wagga & 16 & $15(94)$ & 104 & $87(84)$ & 120 & $102(85)$ \\
\hline Albury & 25 & $14(56)$ & 96 & $80(83)$ & 121 & $94(78)$ \\
\hline Leeton & \# & \# & \# & \# & 37 & $34(95)$ \\
\hline Junee & 3 & $3(100)$ & \# & \# & 3 & $3(100)$ \\
\hline Balranald & 7 & $3(43)$ & 23 & $18(78)$ & 30 & $21(70)$ \\
\hline Hillston & 0 & 0 & 6 & $6(100)$ & 6 & $6(100)$ \\
\hline Temora & 3 & $1(100)$ & 3 & $2(67)$ & 6 & $3(50)$ \\
\hline Wamba Wamba & 3 & $3(100)$ & 10 & $7(70)$ & 13 & $10(77)$ \\
\hline Brungle & 2 & $2(100)$ & 12 & $12(100)$ & 14 & $14(100)$ \\
\hline Cootamundra & 2 & $2(100)$ & 7 & $7(100)$ & 9 & $9(100)$ \\
\hline Tumut & 7 & $7(100)$ & 13 & $11(85)$ & 20 & $18(96)$ \\
\hline Dareton & \# & $\#$ & \# & \# & 126 & $78(62)$ \\
\hline Wentworth & \# & \# & \# & \# & 46 & $34(74)$ \\
\hline Buronga & \# & \# & \# & \# & 37 & $23(62)$ \\
\hline Narrandera & \# & \# & \# & \# & 112 & $92(82)$ \\
\hline Darlington Pt & 2 & $2(100)$ & 9 & $9(100)$ & 11 & $11(100)$ \\
\hline Hay & 3 & $3(100)$ & 17 & $17(100)$ & 20 & $20(100)$ \\
\hline Griffith & \# & $\#$ & $\#$ & \# & 121 & $84(69)$ \\
\hline Deniliquin & $\#$ & \# & \# & \# & $\#$ & $\#$ \\
\hline Total (of available data) & 73 & $55(75)$ & 299 & $253(85)$ & 852 & $657(77)$ \\
\hline
\end{tabular}

\# Data not available

years were harder to identify, and it was sometimes difficult to arrange for immunisation. Although 196 infants were identified in the high-risk neonate program, and 119 fully immunised, we suspect many pre-school children were not identified or immunised in either program. It is likely that a proportion of the school-age children immunised had already been infected with $\mathrm{HBV}^{2,3}$ and therefore gained no benefit from immunisation. Since infants and young children are at the highest risk of acquiring the infection and becoming chronic carriers ${ }^{4}$, they should be the main targets of any immunisation campaign.

Possible explanations for the failure to identify eligible children and the poor completion rates in some areas include inadequate promotion of the program in the target communities, limited resources, regional and local organisational problems and the transient nature of some Aboriginal populations. Promotion was an issue particularly in the larger communities, and many parents of pre-schoolers may not have been aware of the availability of immunisation and its importance. Since the SWR is an area in which resettlement of Aboriginal people was undertaken, some communities are composed of people from different areas and tribal groups who may not necessarily interact and it was often difficult to gain access to everyone to promote hepatitis B immunisation.

The program identified that many Aboriginal people were aware of the problem of hepatitis B and that the disease could be prevented by immunisation. However the importance of children receiving immunisation was not clearly understood and there was concern over why the vaccine was not made available to teenagers and adults. Although only Aboriginal children were being immunised at school, the issue of discrimination did not arise. Good cooperation was achieved between the Aboriginal communities and Community Health staff involved in the program and important links were formed which may facilitate future preventative health initiatives.

In conclusion, it appears the program failed to identify and immunise many eligible children in the Region. Overall a reasonable to good coverage of those children commencing the course was achieved, although completion rates were low in some communities. Our experience indicates that good organisation and a wellprepared program promotion are vital to ensure that children who need immunisation are identified, and that they complete the course.

This evaluation was conducted on the basis of immunisation coverage, but another important measure of the success of an immunisation program is the protective efficacy of the vaccine. Further evaluation of vaccine immunogenicity and efficacy in target groups in Australia is important to determine overall program success.

Anthony Kolbe,

Associate Director, Public Health Unit, South West Region Roslyn Riley,

Hepatitis B Coordinator, South West Region

Christopher Maher,

Director of Community Health Services, Wagga Wagga

1. Thomas N. Aboriginal Health - Current Status. Aust NZ J Med 1984 1. Thomas

2. Beasley RP, Trepo C, Stevens CE, Szmuness W. The e antigen and 2. Beasley $R P$, Trepo $C$, Stevens $C E$, Szmuness $W$. The e antigen and vertical transmis

1977; 105:94-98.
3. Beasley RP, Hwang LY, Lin CC et al. Incidence of hepatitis B virus 3. Beasley RP, Hwang LY, Lin CC et al. Incidence of hepatitis
infections in pre-school children in Taiwan. J Infect Dis 1982; 146:198-204.

4. Gardner ID, Wan X, Simms PA, Worswick DA, Burrell CJ, Mathews JD. Hepatitis B virus markers in children and staff in Northern Territory schools. Med J Aust 1992; 156:638-641 